\title{
Scales of variation of gastropod densities over multiple spatial scales: comparison of common and rare species
}

\author{
M. G. Chapman*, A. J. Underwood \\ Centre for Research on Ecological Impacts of Coastal Cities, Marine Ecology Laboratories A11, University of Sydney, \\ New South Wales 2006, Australia
}

\begin{abstract}
Quantifying spatial variation of populations of animals and plants is fundamental to understanding the relative importance of different ecological processes that influence them. Smallscale patterns in marine invertebrate densities are often thought to be determined by organisms' responses to very localized cues, e.g. quality of habitat or food. In contrast, large-scale patterns have often been attributed to much larger-scale processes, such as availability of larvae, wave-action or upwelling. However, if features of habitat (which primarily influence populations at a small scale) vary over larger spatial scales, population variation over these larger scales may be due entirely to local responses to habitat occurring at a small scale. This study used artificial units of habitat (AUHs) to standardize features of habitat, in order to measure rates of colonization of subtidal gastropods at scales of $20 \mathrm{~cm}$ to $4 \mathrm{~km}$. Patterns were compared for 8 common and 6 rare species, in addition to the assemblage of gastropods. Many of the species that colonized these AUHs were found in similar densities to those in natural habitats. Despite the standardisation of habitat, all species showed smallscale differentiation among AUHs only $20 \mathrm{~cm}$ apart, again mimicking patterns in natural patches of habitat. This was most probably due to choices of whether to colonize or not, rather than passive colonization forced by local environmental factors, because different species showed different patterns of colonization among AUHs. There was little additional variation in numbers across scales from $1 \mathrm{~m}$ to $4 \mathrm{~km}$. The rare species showed greater small-scale and less large-scale variation than did the common species, but species in each group did not show similar patterns among individual AUHs. Where there are infrequent sample units that have large numbers of individuals (or species), they affect means at larger scales, causing larger-scale variation. Understanding small-scale responses to habitat must underpin studies of broad-scale patterns, so that changes in local processes having influences over large scales can be differentiated from broad-scale processes. This also has large implications for assessments of environmental impacts and monitoring of biodiversity, two of the most important tasks for ecologists in the immediate future.
\end{abstract}

KEY WORDS: Artificial habitat $\cdot$ Gastropoda $\cdot$ Patchiness $\cdot$ Spatial scales $\cdot$ Variation

\section{INTRODUCTION}

Identifying the scales at which populations of animals and plants vary in abundance has long been recognized as an important issue in ecology (Greig-Smith 1952, Taylor 1961, Levin 1992), although it has recently received increased attention (Denny et al. 2004). Typi- cally, for many if not all species, local abundances change at a hierarchy of scales, depending on e.g. their size, mobility, and life-histories, and there are no obvious or intrinsically correct scales at which abundances of species should be measured (Levin 1992, Beever et al. 2006). Thus, small taxa with rapid rates of reproduction typically show considerable small-scale variability 
at the scale of hours to days (Thistle 1981, Levin 1984, Morrisey et al. 1992a), or from millimetres up to metres (Morrisey et al. 1992b, Underwood \& Chapman 1996, Chapman 2005), while large organisms with slower rates of increase, or those that form large colonies, can have relatively stable populations over years or decades (Connell 1978) and may show relatively little small-scale spatial patchiness in abundances.

Quantifying how populations differ over multiple spatial scales allows one to focus on the variety of ecological processes that influence organisms. Small-scale variability may be controlled by behavioural responses to other biotic (e.g. Jernakoff 1985) or abiotic features of habitat (Underwood 2004). At larger scales, factors affecting recruitment or mortality may be increasingly important (Gaines et al. 1985, Benedetti-Cecchi et al. 2005); at the very largest scales, broad-scale environmental factors, such as climate or water circulation (Shkedy \& Roughgarden 1997), may be the dominant factors influencing distributions and abundances. Patterns that are only apparent at larger spatial scales may, however, be due to small-scale responses to local habitat, if the habitat itself changes in quality across larger scales. Such patterns could easily be interpreted as due to broader environmental cues when they are in fact due to changes in responses to local cues, but it is the cues themselves that change over larger scales (Helmuth et al. 2006, Rilov \& Schiel 2006).

Typically, there is a close association between measures of local abundance, proportion of sites occupied and geographic range (Gaston 1994), although these characteristics are not necessarily independent. Common species are typically reported to occupy many sites and have large abundances, with local abundance decreasing at the edge of the range, although there are strong criticisms of the generality of this pattern (Sagarin \& Gaines 2006). Many rare species have small abundances or only occur in few sites over a limited geographic range, possibly because of habitatspecificity (Gaston 1994). Other rare species can be widespread, while only occupying few sites, or having very small populations (Gaston 1994) over this range. Rare species may therefore show less relationship between local abundance and occupancy of potential sites. Many rare species of marine invertebrates appear to be sparsely distributed because they are only sampled in few replicates. Many of the comparisons of relationships between population abundance and occupancy of patches have necessarily compared across very different taxa, or very different spatial scales (Gaston 1994).

Marine invertebrates may show fundamentally different patterns of structure of populations at varying spatial scales from those shown by terrestrial taxa because (1) larvae are often widely dispersing (Schel- tema 1971) and (2) the water-column that connects nearby populations may be used as a dispersive medium by both larvae and adults (Scheltema 1971). Many studies show that populations have considerable small-scale variability in space and in time (e.g. Morrisey et al. 1992a,b, Underwood \& Chapman 1996). In fact, many populations of marine organisms appear dominated by small-scale variability and rare populations and the traditional definitions of rarity may not be relevant for marine invertebrates (Chapman 1999).

In order to separate 2 scales of processes potentially causing differences in large-scale patterns in abundance, i.e. those due to local environmental conditions (e.g. supply of propagules) and those due to changes in local quality of habitat over a larger scale, one experimental method has been to provide artificial patches of habitat for colonization in different places (Myers \& Southgate 1980, Hall et al. 2000). At least in the short-term, these provide consistent features of habitat so any differences in colonization among places is not likely to be due to features of habitat. If larger-scale processes, e.g. processes affecting water movement, are more important in determining occupancy of habitat, there should be larger variation among locations or sites than at smaller spatial scales. In contrast, if occupancy of patches of habitat is primarily an outcome of behavioural or other small-scale responses to features of different patches, there should be large variation among units of habitat within the large scales, but less variation at larger scales themselves.

In marine habitats, artificial units of habitat (AUHs) include fouling plates of various sorts (Dean 1981), bottle brushes (Atilla \& Fleeger 2000), sandstone or concrete blocks (Chapman 2003), mimics of seagrass or algae (Edgar 1991) and plastic pot-scourers (Gee \& Warwick 1996, Underwood \& Chapman 2006). Various studies have shown that AUHs can successfully provide habitat for a wide range of meio- and macrofauna on intertidal and subtidal rocky habitats and soft sediments. The degree to which they are colonized by the full range of natural fauna in the habitat they are attempting to mimic is not always clear. Nevertheless, to quantify scales of variation of colonization of habitat by individual species, rather than to recreate the full assemblage, it is not necessary that all species respond to AUHs as natural habitat.

Plastic pot-scourers are colonized by a wide range of benthic macrofauna, including crustaceans, polychaetes and gastropods (Gee \& Warwick 1996, Underwood \& Chapman 2006). They are a recommended artificial habitat for examining spatial differences in biodiversity of benthic invertebrates (Gee \& Warwick 1996), examining the process of succession (Underwood \& Chapman 2006) and measuring disturbances. 
For them to be useful in testing hypotheses, it is, however, necessary to understand spatial variation at which benthic fauna colonize artificial habitats before experiments can be efficiently designed to test more specific hypotheses.

Gastropods can colonize AUHs, such as pot-scourers, as recruits, or as adults via crawling, or drifting through the water-column. Gastropods form a diverse assemblage, are consistently easy to identify and include species with very different relative abundances, lifehistories, trophic levels, and responses to environmental stresses. Their patterns of colonization can be similar to those of a much larger and diverse assemblage (Smith 2005, authors' unpubl. data). Therefore, they are a useful taxocene to measure colonization, and spatial variation in their patterns of abundance is probably fairly representative of a broader assemblage.

This study used plastic pot-scourers deployed at scales of centimetres to kilometres to measure colonization of subtidal gastropods. Specific hypotheses being tested were that locally common and locally rare species would show consistently different patterns of variation (i.e. rare species would be similar to each other, but consistently differ from common species, which would also be similar), with respect to the scales at which there was significant variation in abundances and the proportion of variation attributable to the different spatial scales. In addition, variation in colonization at scales from centimetres to kilometres was quantified for all the gastropods, in addition to individual taxa, to develop an understanding of the spatial variability in the assemblage and how it relates to the rates of colonization and variability in numbers of individuals of the component species.

\section{MATERIALS AND METHODS}

Sampling. AUHs were deployed subtidally at a depth of about $6 \mathrm{~m}$ on rocky reefs at a range of nested spatial scales. In each of 2 bays approximately $4 \mathrm{~km}$ apart, Long Bay and the Cape Banks Scientific Marine Research Area, immediately north of Botany Bay (New South Wales, Australia), AUHs were deployed in each of 2 sites, about $200 \mathrm{~m}$ apart. In each site, there were 2 plots, approximately $20 \mathrm{~m}$ apart and in each plot, a grid of 4 black PVC mats was attached to the rock, with about $1 \mathrm{~m}$ between the centres of each mat. Note that the bays are naturally patchy in terms of e.g. habitat, cover of algae, and patches of sediment. So, all sites, plots and positions where mats were deployed represent considerable natural variation in terms of local habitat.

The mats were attached to patches of substratum with encrusting algae, but away from beds of foliose algae. Each mat had 5 AUHs, about $20 \mathrm{~cm}$ apart (see Fig. 1a.i). AUHs were built of commercially available plastic pot-scourers, approximately $10 \mathrm{~cm}$ in diameter and $3 \mathrm{~cm}$ thick. Each scourer was attached to a backing board (Underwood \& Chapman 2006), with the boards attached to the mats using cable ties.

After deployment for approximately 4 mo, each AUH was collected by coring around the AUH without disturbing it, through to the backing board (Underwood \& Chapman 2006). Each corer had $63 \mu \mathrm{m}$ mesh netting across the top surface to allow water, but not macrofauna, to escape through the top of the corer. The cored section of the foam sealed the other end of the corer, with the assemblage trapped inside the corer. Pilot studies showed that this method minimized loss of animals compared to methods that dislodged the AUH from the substratum.

The AUHs were preserved in $7 \%$ formal-seawater, then removed from the backing plate, unravelled and washed, with the backing plate, over a $500 \mu \mathrm{m}$ mesh sieve. Each sample was then examined for approximate abundances of fauna. Samples with relatively few animals (approximately $<200$ individuals) were sampled completely. Those with larger abundances were divided into subsamples and random subsamples sorted to a maximal time limit per AUH. Most gastropods were identified to species or morphospecies (i.e. consistently identified, but not formally named, sensu Oliver \& Beattie 1996), although Opisthobranchs and Triphoridae were not further distinguished.

Analyses. The original plan was to analyse spatial variation at the scale of reefs (4 km apart), sites (200 m apart), plots (20 $\mathrm{m}$ apart), mats (1 $\mathrm{m}$ apart) and individual AUHs (20 cm apart) for species with different abundances and, separately, with different levels of frequency of occurrence (with respect to number of AUHs occupied). This would separately evaluate the effect of overall abundance and overall frequency of occurrence on spatial scales of variability. This design was subsequently modified because of the strong correlation between abundance and frequency of occurrence. Therefore, species were selected to represent 3 different levels of abundances.

For selected species and for the assemblage of gastropods (or, more correctly, the taxocoene, hereafter called an assemblage), hierarchical analyses of variance was used to (1) identify the spatial scales (locations, sites, plots or mats) at which there was significant variation and (2) extract the components of variation from the mean square (MS) estimates for each spatial scale independently. This was done using the methods described by Fletcher \& Underwood (2002), thus correcting for negative estimates of variances. 
For the assemblage, PERMANOVA (Anderson 2001) was similarly used to analyse Bray-Curtis dissimilarities calculated from untransformed data and components of variation extracted from the MS estimates as in traditional analyses of variance.

To test hypotheses that variances measured at small scales are themselves consistent over larger scales, a series of analyses was done, each with 2 different steps. First, variances (for the individual species) or Bray-Curtis dissimilarities (for the assemblage) were calculated between random pairs of AUHs and, separately, among all AUHs in a treatment. The former provide direct and independent estimates of variation at the smallest spatial scale (Underwood \& Chapman 1998), whereas the latter provide the best average estimate of dissimilarity for that scale (see 'Results' for details). Similarly, for each of the selected species, variances were calculated between pairs of replicates at a particular scale, or among all replicate AUHs at that scale.

Once these estimates of variation were extracted, they were compared across larger spatial scales to test the hypothesis that the magnitude of the small-scale variation does not, itself, vary across larger spatial scales. As a specific example, calculating BrayCurtis dissimilarities (or variances) across all AUHs on each mat can provide a measure of variation at the scale of centimetres for the assemblage and for selected species, respectively (Fig. 1a.ii). These data are nonindependent within each mat, but the mean for each mat provides an independent estimate and can be treated as a replicate measure. These measures (transformed to natural logarithms in the case of the variances) can be analysed in hierarchical analyses of variance to test the hypotheses that small-scale variability is consistent across larger spatial scales, or that small-scale variability itself changes as sampled areas become further apart.

In addition, using the same example, pairing random AUHs per mat provides 2 independent measures of dissimilarity (Fig. 1a.iii). These can be similarly analysed, with 2 estimates of variation per mat, allowing tests of change in variability from one mat to another in a plot (i.e. at the scale of metres).

Full details of similar extensions to the analyses are given in the 'Results'.

\section{RESULTS}

There were 85 species or morphospecies (hereafter referred to as species), plus Opisthobranchs and Triphoridae. In addition, a few juvenile gastropods and limpets could not be identified and were referred to as unidentifiable. Other than the Opisthobranchs, these were very rare, totaling $29(0.3 \%)$ individuals of a total of 9310 individuals. There were 133 Opisthobranchs (1.4\% of all individuals).

Numbers of individuals varied from 3569 (Amphithalamus incidatus) to 28 species that were only found as singletons. A further 22 taxa were found as 2 to 5 individuals across all AUHs.

\section{Spatial scales of variability}

There was a strong correlation between the abundance of the different species and the number of AUHs

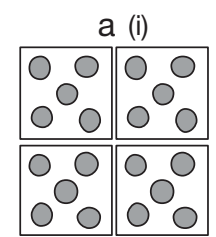

Each plot

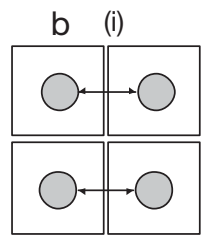

Using mat centroids to give 2 independent measures per plot

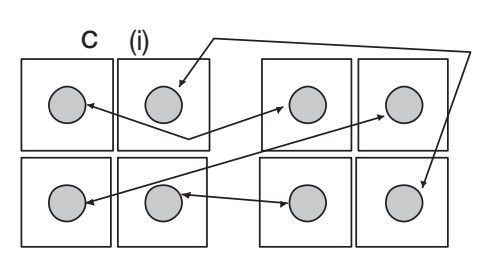

Two plots

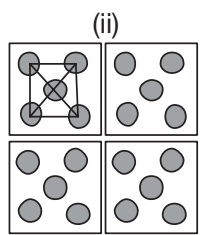

Using all AUHs to give 1 centroid per mat

(ii)

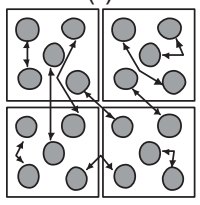

Using individual AUHs paired within or across mats

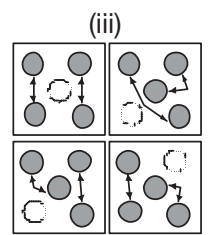

Using independent pairs to give 2 measures per mat

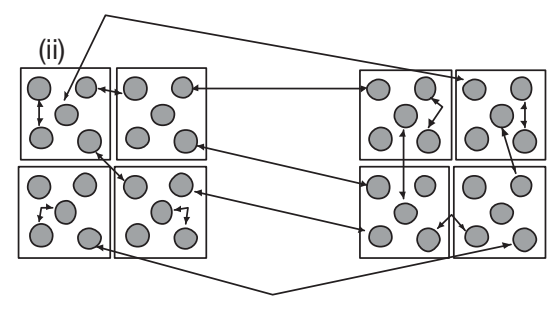

Fig. 1. Design for extractions of univariate and multivariate estimates of variance at small scales for tests of generality of magnitudes across larger scales. (a.i) Five AUHs (artificial units of habitat) in each of 4 mats in a plot; (a.ii) using all AUHs per mat to calculate 1 variance per mat; (a.iii) using pairs of AUHs to calculate independent variance per mat; (b.i) using averages (centroids) per mat to calculate variance between mats; (b.ii) using pairs of AUHs to calculate independent variances within and between mats; (c.i) using averages (centroids) per mat to calculate variance between plots; (c.ii) using pairs of AUHs to calculate independent variance within and between mats and between plots (details in 'Materials and methods: Analyses') 
they occupied (Fig. 2). This indicated no logical basis for selecting species according to their overall abundance and, separately, their frequency of occurrence, because these 2 approaches selected the same sets of species. Therefore, species were selected according to their total abundance across all samples.

The 8 most abundant species (mean density $>1.5$ per AUH) analysed were Amphithalamus incidatus (3569 individuals), Rissoella micra (1902), Crassitoniella flammea (655), Mitrella sp. (473), A. pyramis (369), Rissoella sp. (352), Tricolia variabilis (336) and Eatoniella atropurpurea (290). Of those with intermediate abun-

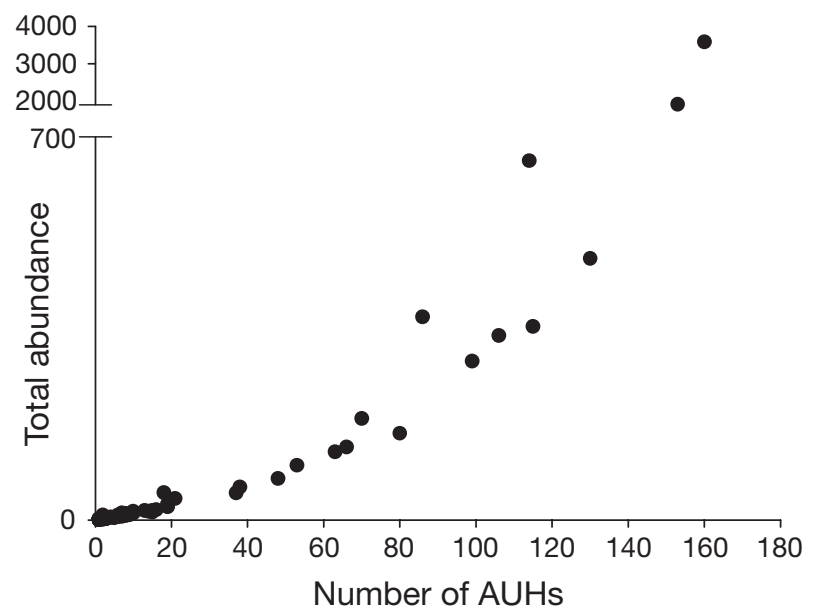

Fig. 2. Overall abundance of each species and the number of AUHs occupied by that species dance (densities in the range 0.45 to 0.75 per AUH), a subset comprising E. galbinia (124), Pisinna albizona (98) and Pseudopisinna gregaria gregaria (76) were analysed. Rare species (densities of 0.15 to 0.20 per AUH) were Lodderina minima (29), Turbo torquatus (27) and Eatonina rubrilabiata (24). The abundances of the remaining taxa were considered too small for analysis.

Six of the 8 abundant species showed significant differences in abundances among mats (1 m apart), 4 differed significantly among plots $(10 \mathrm{~m}), 1$ differed significantly at the scale of sites $(200 \mathrm{~m})$ and 1 at the scale of bays $(\mathrm{km}$; Table 1$)$. All species showed significant variation at one or more scales; 5 of these only varied significantly at one scale.

For example, Amphithalamus incidatus showed considerable variability, although only the scale of mats was significant (Table 1; Fig. 3a, see particularly Site 2, Plot 2). As shown by the magnitudes of the components of variation for each spatial scale, there was also considerable variation in this species between plots (see, for example, the 2 sites in Location 2 in Fig. 3a). The means in the 2 locations also differed substantially, largely due to greater numbers in many of the plots in Location 2. Patterns in Crassitoniella flammea were similar to those of A. incidatus, both in terms of the relative sizes of components of variation for the different spatial scales (Table 1) and with respect to the particular plots which showed much or little variation among mats and the sites which showed greatest variation between plots.

Table 1. Components of variation for each of 5 spatial scales from locations $(\mathrm{km})$ to replicates (cm; see 'Materials and methods: Analyses' for details; $\mathrm{n}=5$ ) for 8 abundant and 6 rare gastropod species and the assemblage. L: Location; S: Site; P: Plot; parentheses indicate nesting of factors. Significance at ${ }^{*} p<0.05,{ }^{* *} p<0.01,{ }^{* * *} p<0.001$

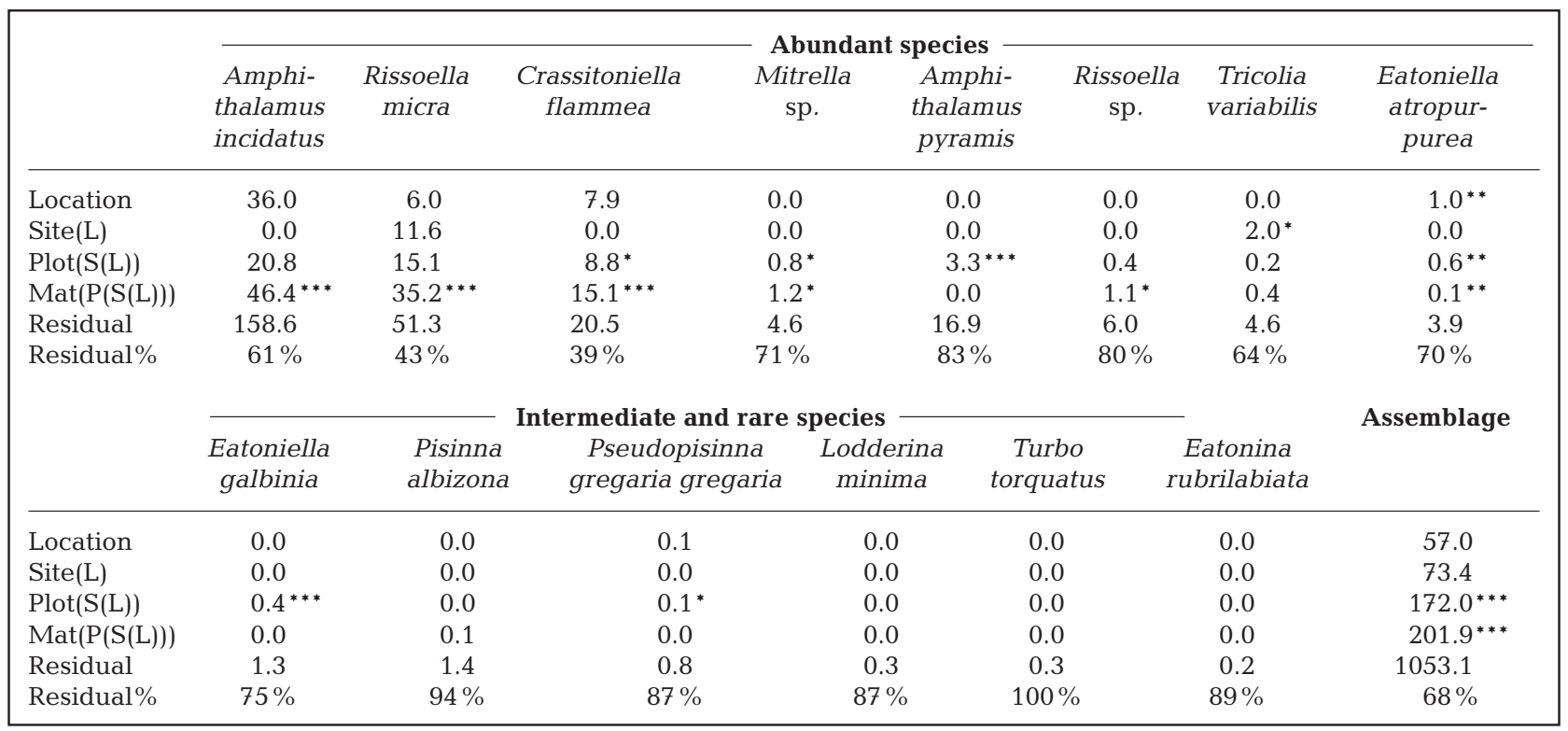



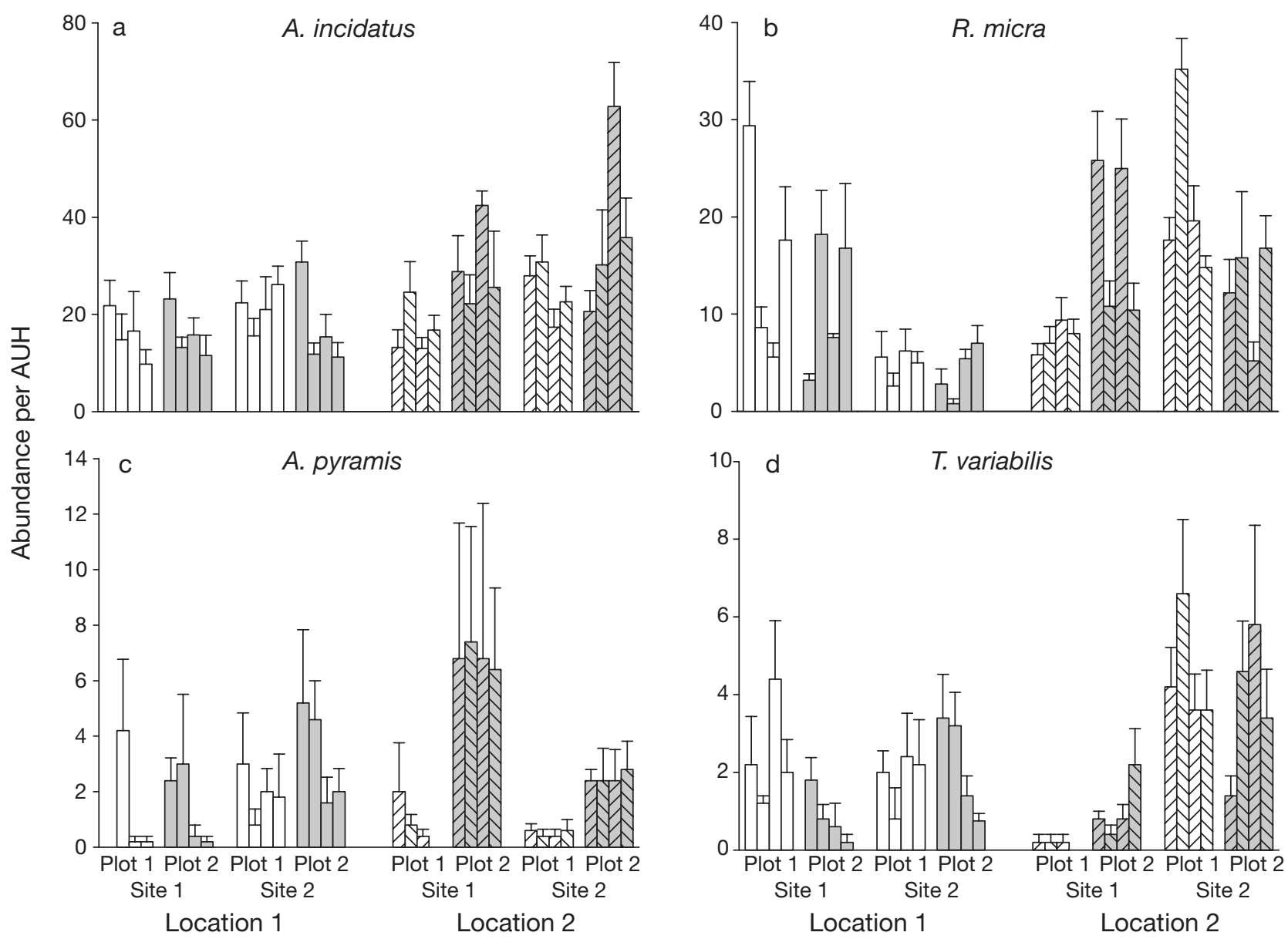

Fig. 3. Mean (+SE) numbers of (a) Amphithalamus incidatus, (b) Rissoella micra, (c) A. pyramis and (d) Tricolia variabilis per AUH for each of 4 mats in 2 plots in 2 sites in 2 locations; $\mathrm{n}=5$

Rissoella micra, in contrast, showed less variation overall (largely due to smaller abundances), but variation among the mats relative to the Residual was greater (component of variation for Mats vs. Residual was 35.2 vs. 51.3) than for Amphithalamus incidatus (component of variation for Mats vs. Residual was 46.4 vs. 158.6; Table 1; see also Fig. $3 b$ ). $R$. micra also showed smaller additional variation across increasing spatial scales, although, in contrast to the other species, all scales added variation to the overall pattern (Table 1).

Three other species (Mitrella sp., Amphithalamus pyramis and Rissoella sp.) showed little variation above their Residuals, accounting for 71, 83 and $80 \%$ of the total variation, respectively, for each species. This extreme level of small-scale variability is illustrated in Fig. 3c for A. pyramis. In contrast to other species, Tricolia variabilis showed little variation at the scale of mats and plots (Table 1). The large component of variation attributable to sites was due to the large difference between sites in Location 2 (Fig. 3d).
None of the 6 less abundant species showed significant variation among Mats and the Residual variation accounted for 75 to $100 \%$ of the total variation for these species (Table 1). In fact, 4 of these (including all 3 rare species) did not vary significantly at any spatial scale. Nevertheless, there was considerable variability among mats in some plots, among plots in some sites and, for some species, greater abundances in Location 2 (see Eatoniella galbinia and Pseudopisinna gregaria gregaria in Fig. 4); however, the latter were not statistically significant, largely because of the large between-plot differences.

The variation among replicate AUHs (i.e. the Residual variation) varied between 39 and $70 \%$ for the most abundant species and between 75 and $100 \%$ for the others. This variation increased as the overall abundance of the species decreased, concomitant with an increasing number of negative estimates of variance for higher terms in the analyses. Therefore, rare species were more patchy at small scales, with little variation at larger scales. Over all species, negative estimates were 


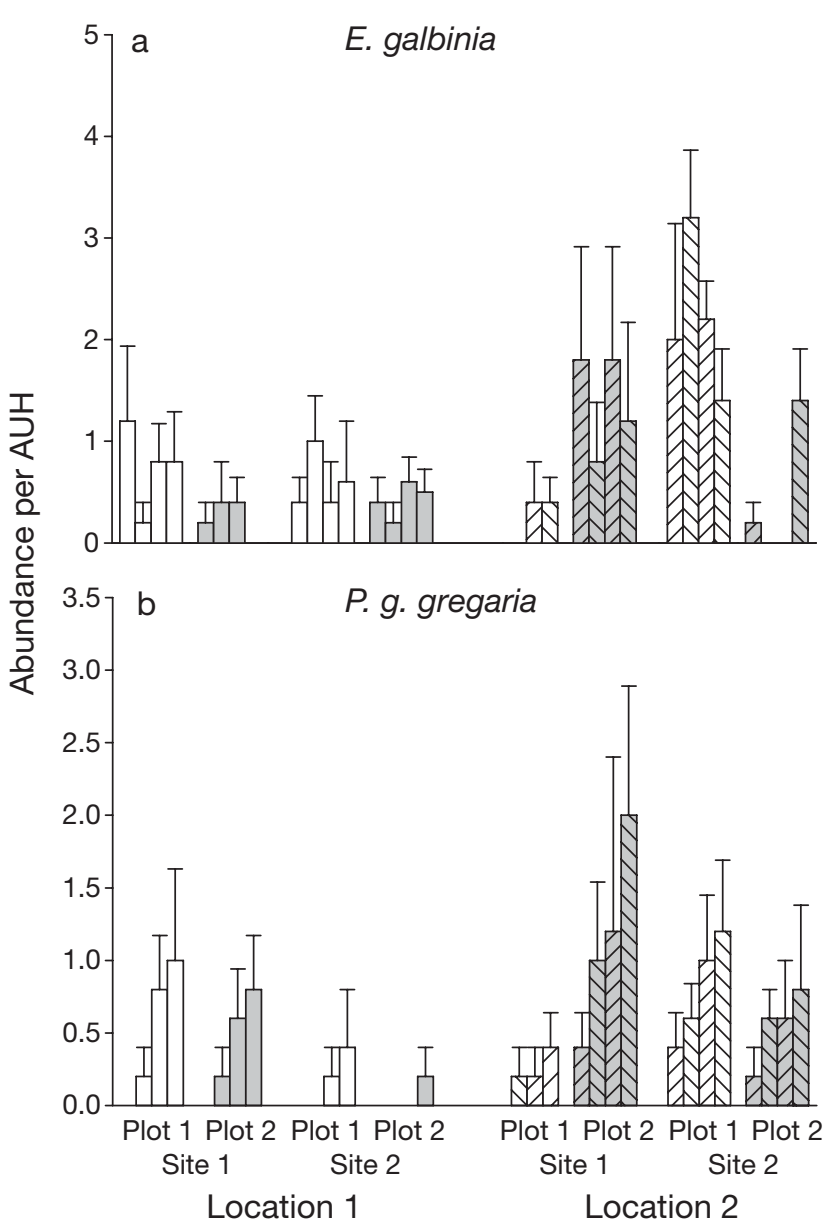

Fig. 4. Mean (+SE) numbers of (a) Eatonina galbinia and (b) Pseudopisinna gregaria gregaria per AUH for each of 4 mats in 2 plots in 2 sites in 2 locations; $\mathrm{n}=5$

more likely for the larger spatial scales (locations and, particularly, sites) than for plots and mats.

The components of variation for the assemblage were similarly extracted from the PERMANOVA (Anderson 2001), after analysis of Bray-Curtis dissimilarities on untransformed data. Unlike the univariate analyses, there were no negative estimates (Table 2), but as was the case for the individual species, significant differences were only found at the smallest spatial scales of mats and plots.

\section{Consistency of small-scale variation across larger special scales}

Scale of centimetres: within mats

To test the hypothesis that the amounts of patchiness at the scale of $20 \mathrm{~cm}$ was similar across larger spatial scales, the variance (individual species) or average dis-

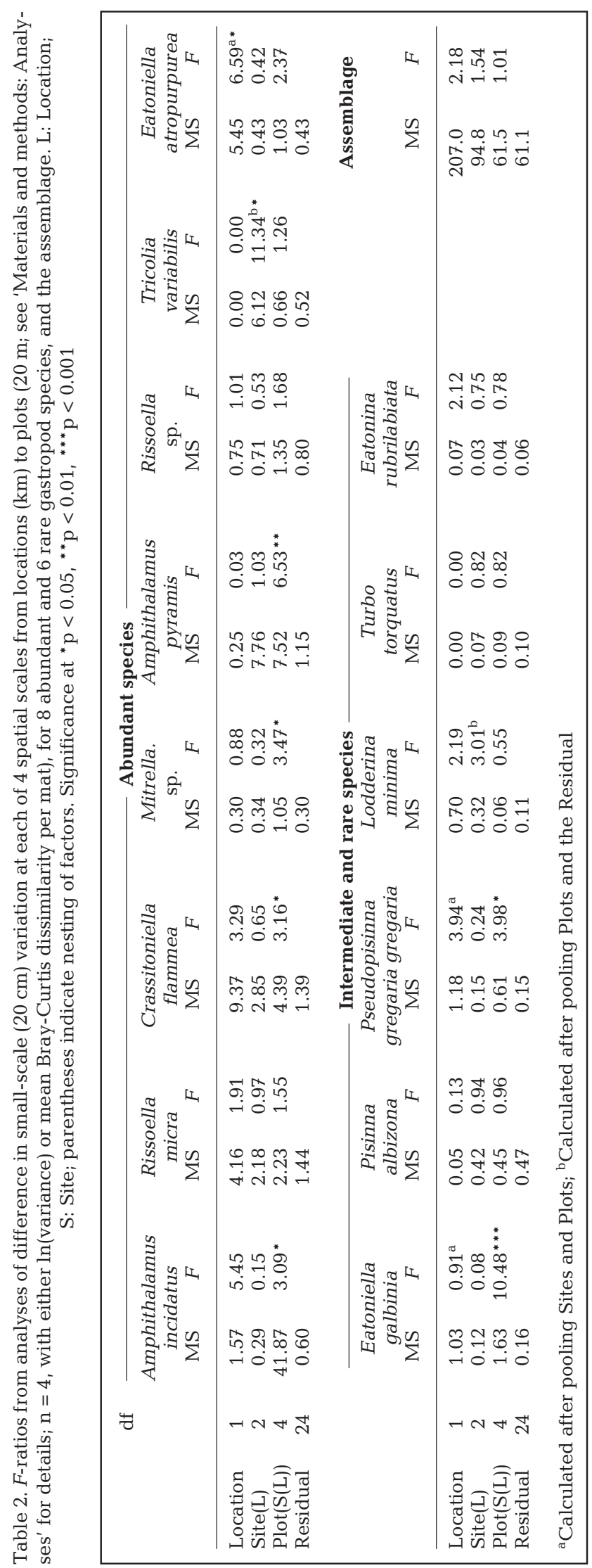


similarity among all pairs of AUHs was calculated for each mat (as described in 'Materials and methods'). These measures were then compared across plots, sites and locations using hierarchical analyses of variance, with the variances for the individual species first transformed to $\ln$ (variance +1 ). Where appropriate ( $p>0.25$; Underwood 1997), terms were pooled to increase power of the tests, or to use more realistic denominators where MS estimates had been underestimated.

Only 1 species, Eatoniella atropurpurea, showed a significant effect of location (Table 2), with the variance in Location 1 (mean $\pm \mathrm{SE}=1.73 \pm 0.41$ ) significantly smaller than in Location $2(6.04 \pm 1.26)$. One species, Tricolia variabilis, showed significant differences among sites (only in Location 2). Six species showed variation at the scale of plots (Table 2), with all showing significant differences between plots in Site 1, Location 2, and 4 species showing significant differences in Site 2, Location 2. All species showed variation in the same direction in Site 1, Location 2, i.e. more variability in Plot 2 than in Plot 1 (shown for Amphithalamus incidatus, A. pyramis and Eatonina galbinia in Fig. 5). The patterns in Site 2, Location 2, however, differed among species. The rare taxa showed similar levels of variability among plots and lack of large-scale changes in this to that shown by the abundant species. The assemblage showed no significant differences at any spatial scale (Table 2 ).

In addition, 2 independent measures were calculated per mat, using 2 pairs of randomly selected AUHs from each mat (Fig. 1a.iii). This was done for the assemblage and the more abundant species, due to large numbers of zero/zero pairs in the data for rare species. These were compared across all spatial scales, from mats to locations, using analyses of variance, to test for consistency of patterns within and between mats at increasing spatial scales.

Only 1 species, Crassitoniella flammea, showed differences among mats, in 1 plot in Site 2, Location 1. The differences identified for other species in the previous analyses were non-significant here, although Tricolia variabilis, in contrast, showed a significant difference between sites in Location 2. There was no significant difference at any scale for the assemblage. Overall, therefore, there was little change in the smallscale (centimetres) variances across scales of metres to kilometres.

\section{Scale of metres: among mats, within plots}

To test the hypothesis that variation at the scale of mats (between samples $1 \mathrm{~m}$ apart), was similar at larger spatial scales, the variances (individual species)

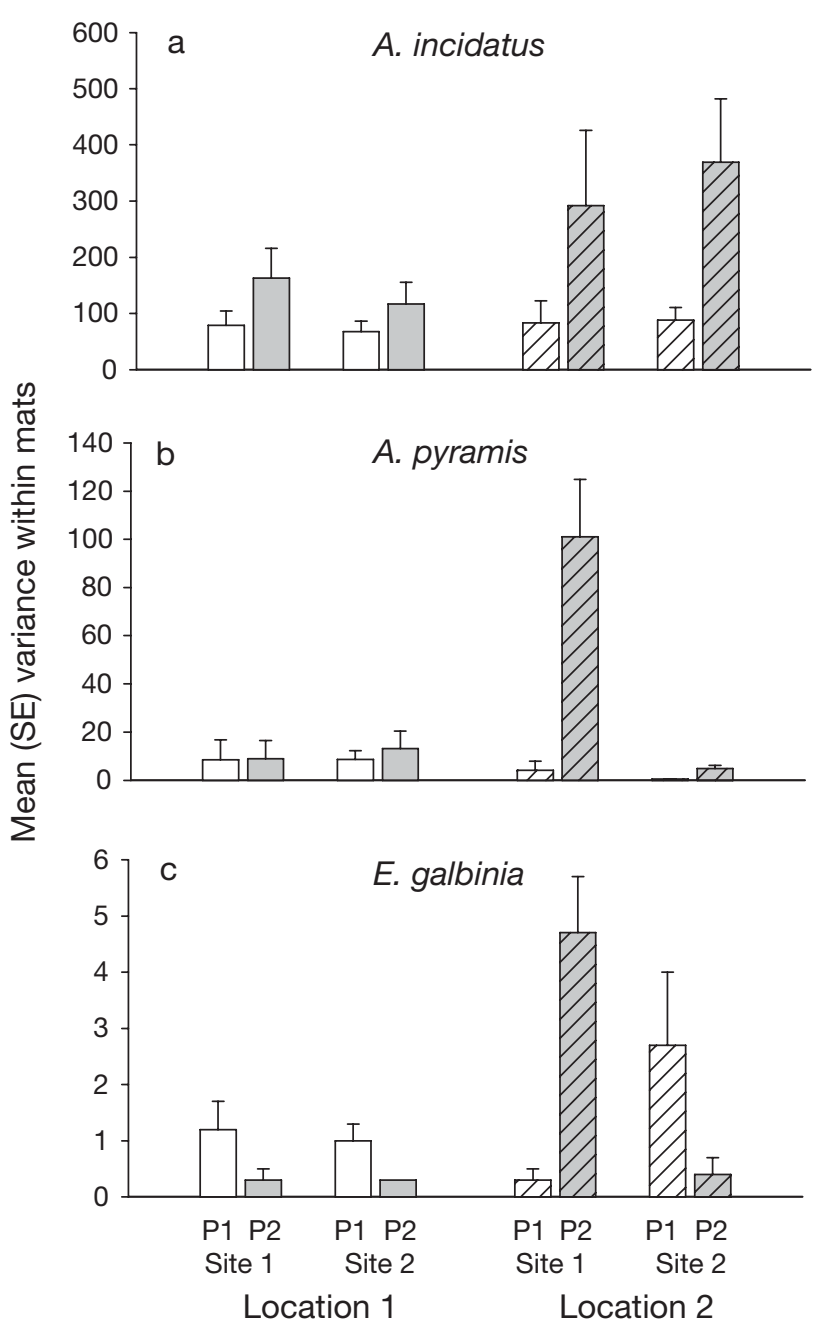

Fig. 5. Mean (+SE) variance among AUHs in each mat (i.e. across a spatial scale of $20 \mathrm{~cm}$ ) for (a) Amphithalamus incidatus, (b) A. pyramis and (c) Eatonina galbinia for each of 2 plots in 2 sites in 2 locations; $\mathrm{n}=4$ replicate mats, each providing a measure of the average variance

or dissimilarity (assemblage) between 2 pairs of mats was calculated using the averages (or centroids) from all AUHs on each mat (Fig. 1b.i). These were then compared across larger spatial scales.

Most analyses did not give significant differences, with only Amphithalamus incidatus, A. pyramis, Pseudopisinna gregaria gregaria and the assemblage differing at the scale of plots (in only 1, 2, 1 and 1 of the 4 sites, respectively) and Crassitoniella flammea and Eatoniella galbinia differing at the scale of sites (each in only 1 location; Table 3 ). Therefore, in general, the amount of patchiness at the scale of about 1 metre was maintained over scales up to kilometres. Although these were not very powerful tests (with relatively few degrees of freedom), the relative sizes of the MS esti- 
mates for the larger spatial scales indicate that lack of significance was not a problem of power (Table 3).

To test the hypothesis that the relative difference between patchiness at scales of $20 \mathrm{~cm}$ (within mats) and $1 \mathrm{~m}$ (among mats) was similar at larger spatial scales, 5 independent variances (dissimilarities) were calculated for within-mat and between-mat differences, using independent AUHs for each calculation. To do this, of the 20 AUHs per plot, 10 were selected (randomly, but so that each of the 5 pairs came from the same mat) to measure within-mat variability and the remaining 10 were paired (i.e. 5 pairs) across random mats (Fig. 1b.ii). These 2 sets of data represent a factor, called Contrast, i.e. between the within- and the among-mat measures. These were then analysed as a fixed factor, orthogonal to the nested scales of plots, sites and locations. For these analyses, only the more abundant species were analysed.

None of these 8 species, nor the assemblage, gave significant values for any terms that included the factor Contrast, even when mean squares were pooled to increase the power of the test. In addition, there was no general tendency for among-mat contrasts to have larger variance than within-mat contrasts; this pattern was shown in 0 to 5 of the 8 plots for the different species). Contrast gave an F-ratio with $0.05<\mathrm{p}<0.10$ for analysis of the assemblage, with among-mat dissimilarities (mean $45 \%$ ) slightly larger than within-mat dissimilarities (mean $35 \%$ ).

Overall, therefore, there was no consistent increase in variance at $1 \mathrm{~m}$ compared to $20 \mathrm{~cm}$ spacing for individual species, although there was a slight increase when the assemblage was considered. The magnitude of these patterns was consistent across larger spatial scales.

\section{Scale of $10 \mathrm{~m}$ : among plots}

To test the hypothesis that variation among plots (the scale of $20 \mathrm{~m}$ ) changes across scales of $200 \mathrm{~m}$ or $4 \mathrm{~km}$, the variance (or dissimilarity) between plots was calculated by independently pairing mat averages (or centroids) to give 4 independent measures per site (Fig. 1c.i). These were analysed as described previously.

All analyses, other than Amphithalamus incidatus, which showed a significant effect of location $\left(F_{1,14}=\right.$ 7.14, $\mathrm{p}<0.05$, after pooling sites and Residual), were non-significant. A. incidatus showed more variation in abundances over $20 \mathrm{~m}$ in Location 2 (mean $\pm \mathrm{SE}=$ $53.1 \pm 20.0)$ than in Location $1(15.9 \pm 13.0)$. No other species, nor the assemblage, gave significant results, nor showed any tendency for patterns to be in the same direction.

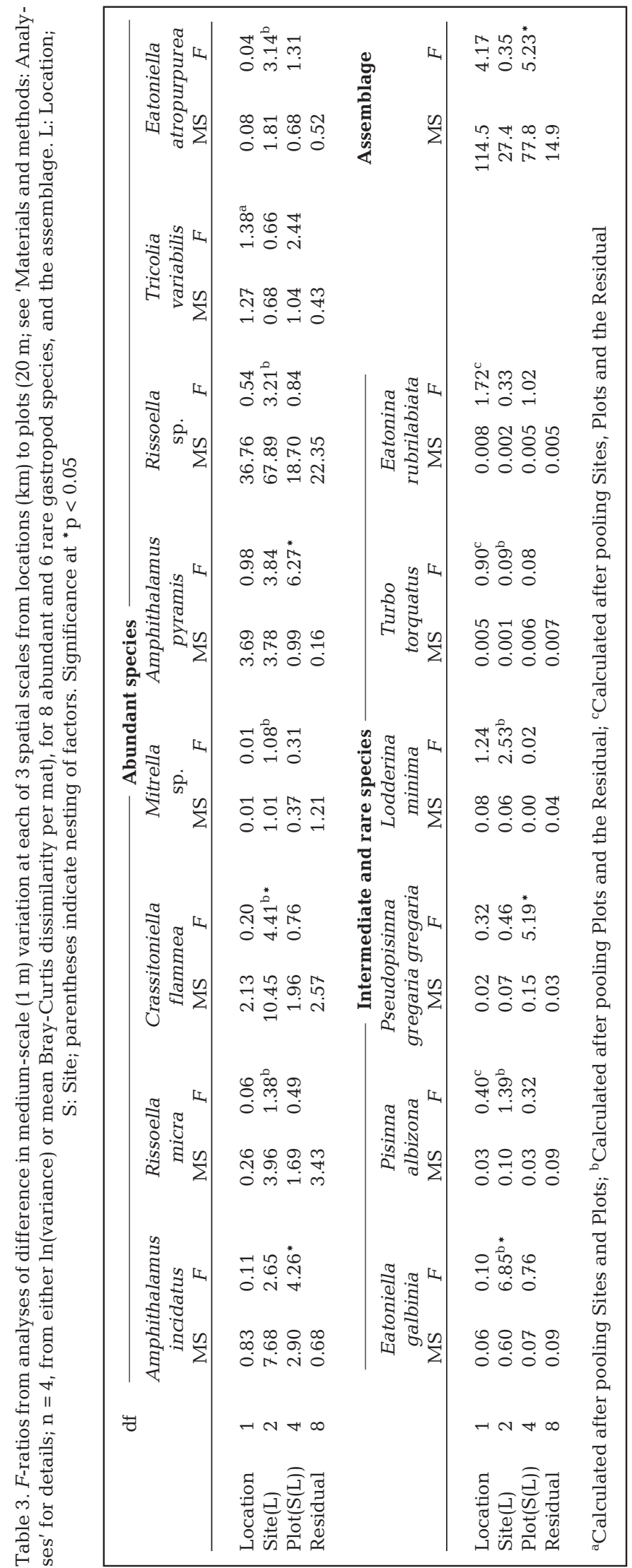


Finally, 5 independent variances (and dissimilarities) were calculated for within-mat/within plot, betweenmat/within-plot and between-plot contrasts, using independent AUHs for each calculation (Fig. 1c.ii). Again, only the common species were tested individually. Similar analyses, using these comparisons as a fixed factor called Contrast, tested whether differences in variability among $20 \mathrm{~cm}, 1 \mathrm{~m}$ and $20 \mathrm{~m}$ were consistent across scales from $200 \mathrm{~m}$ to $\mathrm{km}$.

No analyses of individual species showed any significant effect of Contrast, nor any interaction of this with sites nor locations. For the assemblage, after pooling the Contrast $\times$ Site(Location) interaction $(p>0.25)$ with the Residual, there was a significant effect of Contrast $\left(F_{2,52}=3.35, \mathrm{p}<0.05\right)$, although a posteriori comparisons (Student-Newman-Keuls tests) could not identify significant differences among means. Nevertheless, the mean dissimilarity among plots (53\%) was slightly larger than that measured within mats $(38 \%)$, or between mats (42\%).

\section{DISCUSSION}

Recent research has repeatedly identified that the largest source of variability in abundances of many organisms is at small spatial scales (centimetres to a few metres; e.g. Kristensen et al. 1985, Morrisey et al. 1992b, Thompson et al. 1996, Underwood \& Chapman 1996). Despite such evidence, there is still a perception that this represents 'noise' and that large-scale processes are the most important in determining distributions and abundances (Peters 1991, Hay 1994). Many small species, however, only make active choices with respect to habitat at small scales (i.e. those scales at which they encounter their habitat and have the option of choice), with large-scale patterns primarily resulting from passive dispersal (Gaines et al. 1985, Shkedy \& Roughgarden 1997). When larvae or dispersing adults arrive in a new site, they can make choices about whether to stay (i.e. settle, or colonize habitat) or not, although settlement of some taxa is passive, e.g. seaweeds (Bellgrove et al. 2004) and some small gastropods (Wigham 1975). Choices to settle or colonize can be determined by large-scale features of habitat (e.g. the presence of a seagrass meadow; Jenkins \& Wheatley 1998), or determined very locally (e.g. if a crevice is or is not available; Underwood \& Chapman 1996). If suitability of small-scale features of habitat varies over larger scales (e.g. the density of fronds within a small patch of algal turf varies over hundreds of metres), then abundances of organisms in turf may vary over similar scales, but still be the result of processes operating at small scales, e.g. choice of whether or not to colonize in response to density of algal fronds, rather than, for example, large-scale processes, such as the availability of colonists.

Local differences in components of habitat may make habitat more or less suitable or attractive in some sites compared to others. In attempts to separate effects of local differences from broader-scale processes, AUHs have sometimes been used (Gee \& Warwick 1996, Underwood \& Chapman 2006). Although many types of AUHs have been shown to provide reliable and quantitative data on spatial or temporal variability in colonization and abundances of individual and sets of species, we used small plastic potscourers (Gee \& Warwick 1996, Underwood \& Chapman 2006).

Despite the fact that all AUHs were physically identical and had exactly the same ages, most variability in abundances was at the smallest scales. The Residual variance (among AUHs on the same mat and only $20 \mathrm{~cm}$ apart) accounted for 39 to $100 \%$ of the variation. These variances are similar to those measured for many of the same or closely related species among cores of algae or sediment of similar size to these AUHs (Olabarria \& Chapman 2001) and among small sandstone cobbles (Chapman 2002). Of the 87 taxa, only 9 species showed significant variation at scales of $1 \mathrm{~m}$ (between mats) or $20 \mathrm{~m}$ (between plots), with only 2 varying significantly at scales of $200 \mathrm{~m}$ (sites) to $4 \mathrm{~km}$ (locations). The lack of significant differences at larger scales was not simply due to lack of power (i.e. small numbers of degrees of freedom) to detect differences. The MS estimates and components of variation were, in fact, small (or zero for the latter). Many components were calculated as small negative values, indicating small sampling error around estimates of zero values of variance components. Small positive errors are equally likely to occur for the same reason, but cannot be differentiated from small positive, but real, non-zero values. Positive errors are therefore included as estimates of non-zero variation, slightly overestimating the true values. The extent of this bias cannot be determined. Small estimated values of components of variance are therefore unreliable to some unknown degree and may really represent zero variance.

The AUHs were held slightly off the substratum, which was coralline crust, with no patches of foliose algae or sediment (a potential source of colonists; Chapman 2002) adjacent to some AUHs. There was thus no immediate adjacent habitat from which animals could have crawled into some AUHs and colonization was most likely due to individuals arriving via the water-column. It is, however, not at all clear whether individuals accumulated in some AUHs, (or mats) compared with others because of passive transport or because of active choice to recruit (or stay once arrived). To distinguish between these alternatives 
requires shorter-term, carefully designed experiments that can separate choice of habitat from local watermovement as mechanisms causing variation among AUHs.

It is not known what governs any choices by the animals. Although physical components of these habitats were consistent, AUHs were gradually colonized by sessile fauna and algae, which would have altered biotic characteristics. Many of these species of gastropods live in sediment in addition to algal turf (Olabarria \& Chapman 2001), showing considerable variability in each habitat. They also rapidly colonize bare rock, with very overdispersed patterns, and colonization is influenced by the location and the substratum on which the rocks lie (Chapman 2002). They therefore appear to respond to a complex set of biotic and abiotic cues.

All species that colonized these habitats were small ( $<5 \mathrm{~mm}$ ) and probably colonized as drifting adults and recruits. Eight common and widespread species (found in $>60 \%$ of all AUHs) were compared to 6 species with more restricted distributions (found in 12 to $40 \%$ of AUHs) to test the hypothesis that rarer species show different patterns of variability across increasing spatial scales from those of abundant species. Rare species may be those that generally have small abundances (but can be widespread), or those with very specific habitat requirements (can be locally abundant in only few places; Gaston 1994). Of course, some species may be rare in the present study simply because the AUHs do not provide appropriate habitat. The mix of abundant and rare species was, however, similar to those found in other studies in natural habitats, such as sediment, algal turf or cobbles (Olabarria \& Chapman 2001, Chapman 2002), apart from Pseudopisinna gregaria gregaria, which had smaller densities in this study. Many of the gastropods colonized the AUHs in very small numbers (33\% were only found as singletons, $28 \%$ as 2 to 5 individuals). Chapman (2003) also showed that many of these small gastropods only colonize new habitat in very small numbers. Therefore, it is more likely that this mix of rare and common species represents natural diversity rather than being an experimental artifact.

There were too few data for tests of any patterns for the rarest species. The animals were scattered among AUHs, mats and plots, with no tendency for them to be found in the same places. Therefore, the major comparison was between very common and more rarely distributed species.

The rare species were even more overdispersed than the common species, with Residual variances of 75 to $100 \%$ and very little quantifiable variation at larger scales. In each of the 6 species examined, 5 to $17 \%$ of all individuals were found in a single $\mathrm{AUH}$, which is not markedly different from dispersion of the 8 common species; 2 to $8 \%$ of individuals of the 8 species were found in a single AUH. The individual AUH with largest abundance was not the same for the different taxa, nor did they tend to be in the same mats or plots. Although there was a slight tendency for there to be fewer animals (common and rare) in Location 1 compared to Location 2, this was only found for some plots. Therefore, large-scale differences in density were due to differences at small scales, i.e. due to a few AUHs with very large abundances causing differences to appear at the scales of plots, sites and locations.

Suppose, as a hypothetical example, that a species is represented by 16 individuals in 160 AUHs (mean density of 0.1 per AUH). If 8 were in $1 \mathrm{AUH}$ (on 1 mat, in 1 plot, in 1 site) and the other 8 were in an AUH in the second location, there would be large variance among AUHs in a set (the difference between 1 AUH with 8 and the others with 0 ). There would also be relatively large variation among mats (8 individuals on 1 mat, 0 on the others) and between sites, but not between locations. Variation in scales of mats and sites is entirely due to small-scale variation among AUHs. If there were, instead, 2 AUHs with 8 individuals on 1 mat, there would be relatively large variation at all scales again due to variation among individual AUHs.

Such an effect is not some artifact of using nonnormally distributed numbers in nested analyses of variance (the calculations of which, as opposed to statistical tests of which, are not much affected by nonnormality). It is a result of a relatively large average at a small scale continuing to be relatively large even when averaged over larger scales.

The assemblage (taxocoene) of the gastropods showed very similar patterns to the individual species. Although patterns in assemblages tend to be dominated by patterns in abundant species, the abundant species in this study showed different patterns among individual AUHs. Thus, small-scale patterns of the assemblage do not simply reflect patterns of individual abundant species. Like the individual species, most variation in the assemblage was at the smallest scales, among individuals AUHs and mats. Unlike the individual species, there were no negative components of variation, suggesting that each increasing spatial scale (from centimetres to kilometres) adds at least some small variance to the overall patterns of variation. There was a negative relationship between the extra amount of variation and the spatial scale separating the AUHs, i.e. as the spatial scale over which comparisons were made increased, the amount of added variation in the assemblage decreased. This was particularly marked over $200 \mathrm{~m}$ to $4 \mathrm{~km}$.

The amounts of variation at small scales, both for individual species and the assemblage, were generally re- 
tained over the larger spatial scales. Thus, the variance in abundances among individual scourers only $20 \mathrm{~cm}$ apart itself varied among mats for 6 species, but only differed between sites or locations for 1 species at each scale. Therefore, patchiness in colonization of the AUHs at scales of $20 \mathrm{~cm}$ varied at scales of $10 \mathrm{~m}$, but seldom at scales of $200 \mathrm{~m}$ to $4 \mathrm{~km}$. Although these analyses were not very powerful, the sizes of the MS estimates suggested that the lack of significant differences at the scales above that of plots could be attributable to lack of power for only one species (Crassitoniella flammea) and for the analysis of the assemblage.

Similarly, variation in colonization at scales of $1 \mathrm{~m}$ (among mats) tended to vary significantly from plot to plot (20 m apart), but not at the larger spatial scales of sites and locations, except for Crassitoniella flammea and Eatoniella galbinia. In this case, the lack of significance for some species (particular Amphithalamus incidatus, Rissoella sp. and E. atropurpurea) and the assemblage may have been a problem of power because the MS estimates for some of the terms were relatively large compared to the Residual MS; however, this was not the case for other species, particularly the rare ones. Therefore, in general, small-scale patchiness at scales from $20 \mathrm{~cm}$ to $1 \mathrm{~m}$ may vary among places $20 \mathrm{~m}$ apart in some sites, but did not generally vary across larger spatial scales once the small-scale differences were factored into the analyses.

These data have important implications, both ecologically and with respect to environmental monitoring. First, processes that cause such small-scale variation in colonization by these gastropods and other marine invertebrates (Lapointe \& Bourget 1999) would need to be clearly understood before we can make decisions about conservation of these fauna. If these reflect very strong responses to very localized cues, then we need to identify what these cues are and what causes them to vary so much. These data indicate that, with respect to these gastropods, the cues are more likely to be biotic than abiotic and that they are established within a few months after habitat is made available. Until we understand what these cues are, we will not be able to make any predictions about how they themselves may change under different conditions, including conditions changed by environmental contamination or disturbance.

Second, small-scale variation in patterns of colonization needs to be separated from processes operating at larger scales before we can understand the scales that matter. This needs data collected in hierarchical designs, as exemplified here, so that the variation for each spatial scale can be independently partitioned from the data. These analyses showed very little consistent change over large scales, with most large-scale changes in abundances primarily due to increased colonization of a few AUHs on a few mats in 1 of the 2 plots. The scale of sites and locations therefore appeared not to affect patchiness in the assemblage (the analyses investigating this gave non-significant results), suggesting that if there are large-scale processes, they affect colonization at small scales, i.e. they create small-scale patterns.

If it is proposed that invertebrate assemblages be monitored to detect environmental changes, smallscale variability needs to be very carefully considered in sampling designs. There are 2 major issues. The first issue is that spatial variation at a small scale affects estimated variation at large scales. Where individuals of a species are highly aggregated, some sampling units at small scales will have large numbers. If these occur infrequently, they will make mean numbers relatively variable at larger scales. Any observed variability at these larger scales is, however, due to smallscale variation, not large-scale processes.

Second, there should always be adequate replication of sampling units (here, the individual AUHs) to ensure that small-scale variance in densities is representatively sampled. Otherwise, the occasional replicate with large numbers will be missed in many samples. For example, if a large number of individuals is found in only 1 in every 5 sample units, the probability of missing such a number in different sizes of samples is 0.51, $0.33,0.11$ for $\mathrm{n}=3,5$ and 10, respectively. Many monitoring programmes have small numbers of replicates.

In addition, unless adequate replication at large scales is included in designs, sampling to detect impacts or effects of management or restoration or conservation at large scales can be compromised. Where there is little variance at larger, intermediate scales (e.g. large average numbers of individuals or species, in few locations), they can be eliminated from analyses, leading to more precision (more degrees of freedom) for analyses of difference at the larger scales. Where there is substantial variation at larger scales, increased replication at those scales is essential. So, for large-scale (including macro-ecological) analyses, knowledge of the smaller scales at which variation is occurring is a prerequisite or sampling designs will be inadequate (Underwood \& Petraitis 1993).

In the cases described here and in many analyses in the literature, there is a lot of small-scale variation. This is due to small-scale processes influencing the arrival, establishment, behaviour and general ecology of the animals. If sensible predictive models about ecological processes and patterns are to be developed, this variation must be described, interpreted, understood and explained before larger-scale pattern can be considered well understood. This requires that small-scale processes be investigated and not just ignored or averaged out. 
Acknowledgements. We thank numerous research support staff at the Centre for Research on Ecological Impacts of Coastal Cities for assistance with deployment and retrieval of AUHs, sorting and data entry and checking. This research was supported by the Australian Research Council through their Special Research Centre Programme, and the University of Sydney. Anonymous referees and Professsor L. BenedettiCecchi made comments which helped us improve the paper.

\section{LITERATURE CITED}

Anderson MJ (2001) A new method for non-parametric multivariate analysis of variance. Austral Ecol 26:32-46

Atilla N, Fleeger JW (2000) Meiofaunal colonization of artificial substrates in an estuarine embayment. PSZN I: Mar Ecol 21:69-83

Bellgrove A, Clayton MN, Quinn GP (2004) An integrated study of the temporal and spatial variation in the supply of propagules, recruitment and assemblages of intertidal macroalgae on a wave-exposed rocky coast, Victoria, Australia. J Exp Mar Biol Ecol 310:207-225

Benedetti-Cecchi L, Bertocci L, Vaselli S, Maggi E (2005) Determinants of spatial pattern at different scales in two populations of the marine alga Rissoella verruculosa. Mar Ecol Prog Ser 293:37-47

Beever EA, Swihart RK, Bestelmeyer BT (2006) Linking the concept of scale to studies of biological diversity: evolving approaches and tools. Divers Distrib 12:229-235

Chapman MG (1999) Are there adequate data to assess how well theories of rarity apply to marine invertebrates? Biodivers Conserv 8:1295-1318

Chapman MG (2002) Early colonization of shallow subtidal boulders in two habitats. J Exp Mar Biol Ecol 275:95-116

Chapman MG (2003) The use of sandstone blocks to test hypotheses about colonization of intertidal boulders. J Mar Biol Assoc UK 83:415-423

Chapman MG (2005) Molluscs and echinoderms under boulders: tests of generality of patterns of occurrence. J Exp Mar Biol Ecol 325:65-83

Connell JH (1978) Diversity in tropical rainforests and coral reefs. Science 199:1302-1310

Dean TA (1981) Structural aspects of sessile invertebrates as organizing forces in an estuarine fouling community. J Exp Mar Biol Ecol 53:163-180

Denny MW, Helmuth B, Leonard GH, Harley CDG, Hunt LJH, Nelson EK (2004) Quantifying scale in ecology: lessons from a wave-swept shore. Ecol Monogr 74: 513-532

Edgar GJ (1991) Artificial algae as habitats for mobile epifauna: factors affecting colonization in a Japanese Sargassum bed. Hydrobiologia 226:111-118

Fletcher DJ, Underwood AJ (2002) How to cope with negative estimates of components of variance in ecological field studies. J Exp Mar Biol Ecol 273:89-95

Gaines S, Brown S, Roughgarden J (1985) Spatial variation in larval concentrations as a cause of spatial variation in settlement for the barnacle, Balanus glandula. Oecologia 67: 267-272

Gaston KJ (1994) Rarity, Chapman \& Hall, London

Gee JM, Warwick RM (1996) A study of global biodiversity patterns in the marine motile fauna of hard substrata. J Mar Biol Assoc UK 76:177-184

Grieg-Smith P (1952) The use of random and contiguous quadrats in the study of the structure of plant communities. Ann Bot Lond 16:293-316

Hall SJ, Gray SA, Hammett ZL (2000) Biodiversity-productiv- ity relations: an experimental evaluation of mechanisms. Oecologia 122:545-555

Hay ME (1994) Species as 'noise' in community ecology: Do seaweeds block our view of the kelp forest? Trends Ecol Evol 9:414-416

Helmuth B, Broitman BR, Blanchette CA, Gilman S and others (2006) Mosaic patterns of thermal stress in the rocky intertidal zone: implications for climate change. Ecol Monogr 76:461-479

Jenkins GP, Wheatley MJ (1998) The influence of habitat structure on nearshore fish assemblages in a southern Australian embayment: comparison of shallow seagrass, reef-algal and unvegetated sand habitats, with emphasis on their importance to recruitment. J Exp Mar Biol Ecol 221:147-172

Jernakoff P (1985) Interactions between the limpet Patelloida latistrigata and algae on an intertidal rock platform. Mar Ecol Prog Ser 23:71-78

Kristensen E, Jensen MH, Andersen TK (1985) The impact of polychaete (Nereis virens Sars) burrows on nitrification and nitrate reduction in estuarine sediments. J Exp Mar Biol Ecol 85:75-91

Lapointe L, Bourget E (1999) Influence of substratum heterogeneity scales and complexity on a temperate epibenthic marine community. Mar Ecol Prog Ser 189:159-170

Levin LA (1984) Life history and dispersal patterns in a dense infaunal polychaete assemblage: community structure and response to disturbance. Ecology 65:1185-1200

Levin SA (1992) The problem of pattern and scale in ecology. Ecology 73:1943-1967

Morrisey DJ, Underwood AJ, Howitt L, Stark JS (1992a) Temporal variation in soft-sediment benthos. J Exp Mar Biol Ecol 164:233-245

Morrisey DJ, Howitt L, Underwood AJ, Stark JS (1992b) Spatial variation in soft-sediment benthos. Mar Ecol Prog Ser 81:197-204

Myers AA, Southgate T (1980) Artificial substrates as a means of monitoring rocky shore cryptofauna. J Mar Biol Assoc UK 60:963-976

Olabarria C, Chapman MG (2001) Comparison of patterns of spatial variation of microgastropods between two contrasting intertidal habitats. Mar Ecol Prog Ser 220:201-211

Oliver I, Beattie AJ (1996) Invertebrate morphospecies as surrogates for species: a case study. Conserv Biol 10:99-109

Peters RH (1991) A critique for ecology. Cambridge University Press, Cambridge

Rilov G, Schiel DR (2006) Seascape-dependent subtidalintertidal trophic linkages. Ecology 87:731-744

Sagarin RD, Gaines SD (2006) Recent studies improve understanding of population dynamics across species ranges. Oikos 115:386-388

Scheltema RS (1971) Larval dispersal as a means of genetic exchange between geographically separated populations of shallow-water benthic marine gastropods. Biol Bull (Woods Hole) 140:284-322

Shkedy Y, Roughgarden J (1997) Barnacle recruitment and population dynamics predicted from coastal upwelling. Oikos 80:487-498

Smith SDA (2005) Rapid assessment of invertebrate biodiversity on rocky shores: where there's a whelk there's a way. Biodivers Conserv 14:3565-3576

Taylor LR (1961) Aggregation, variance and the mean. Nature 189:732-735

Thistle D (1981) Natural physical disturbances and communities of marine soft bottoms. Mar Ecol Prog Ser 6:223-228

Thompson RC, Wilson BJ, Tobin ML, Hill AS, Hawkins SJ (1996) Biologically generated habitat provision and diver- 
sity of rocky shore organisms at a hierarchy of spatial scales. J Exp Mar Biol Ecol 202:73-84

Underwood AJ (1997) Experiments in ecology. Their logical design and interpretation using analysis of variance. Cambridge University Press, Cambridge

Underwood AJ (2004) Landing on one's foot: small-scale topographic features of habitat and the dispersion of juvenile intertidal gastropods. Mar Ecol Prog Ser 268:173-182

Underwood AJ, Chapman MG (1996) Scales of spatial patterns of distribution of intertidal invertebrates. Oecologia $107: 212-224$

Underwood AJ, Chapman MG (1998) A method for analysing spatial scales in variation in composition of assemblages.

Editorial responsibility: Roger Hughes,

Bangor, UK
Oecologia 117:570-578

Underwood AJ, Chapman MG (2006) Early development of subtidal macrofaunal assemblages: relationships to period and timing of colonization. J Exp Mar Biol Ecol 330:221-233

Underwood AJ, Petraitis PS (1993) Structure of intertidal assemblages in different localities: How can local processes be compared? In: Ricklefs RE, Schluter D (eds) Species diversity in ecological communities historical and geographical perspectives. University of Chicago Press, Chicago, IL, p 39-51

Wigham GD (1975) The biology and ecology of Rissoa parva (da Costa)(Gastropoda: Prosobranchia). J Mar Biol Assoc UK 55:45-68

Submitted: May 7, 2007; Accepted: August 8, 2007

Proofs received from author(s): January 15, 2006 